РУБВАЛЬТЕР Дмитрий Александрович - доктор экономических наук, профессор, советник директора Московского центра технологической модернизации образования «ТемоЦентр» (107076, Россия, г. Москва, 1-й Зборовский пер., 3; dmitry.rubvalter@yandex.ru)

МАРКУСОВА Валентина Александровна - доктор педагогических наук, заведующий отделением Всероссийского института научной и технической информации РАН (140010, Россия, г. Москва, ул. Усиевича, 20; valentina.markusova@gmail.com)

ЛИБКИНД Илья Александрович - аналитик Сервисного бюро VIP (111394, Россия, г. Москва, ул. Перовская, 65; ilya_libkind@hotmail.com)

КАМЕНЬ Наталья Марковна - старший научный сотрудник Всероссийского института научной и технической информации РАН (140010, Россия, г. Москва, ул. Усиевича, 20; natakhak@mail.ru)

ЛИБКИНД Александр Наумович - кандидат технических наук, ведущий научный сотрудник Всероссийского института научной и технической информации РАН (140010, Россия, г. Москва, ул. Усиевича, 20; anliverty@mail.ru; тел 89169471953)

\title{
ДИНАМИКА ХАРАКТЕРИСТИК ПУБЛИКАЦИОННОЙ АКТИВНОСТИ В РОССИЙСКОЙ ФУНДАМЕНТАЛЬНОЙ НАУКЕ В СОПОСТАВЛЕНИИ СО СТРАНАМИ БРИК
}

Аннотация. В статье проводится анализ ряда формальных параметров, характеризующих публикационную активность российских ученых в сопоставлении со странами БРИК и мировым потоком публикаций в целом. В частности, это динамика ежегодного числа публикаций, темпы изменения этого числа, динамика изменений доли публикаций в мировом потоке, распределение российских публикаций по языкам их опубликования, соавторство на уровне стран. Анализ охватывает период 1993-2017 гг. и основывается на обработке данных Web of Science.

Ключевые слова: публикационная активность, российская наука, страны БРИК, наукометрия, Web of Science

B последние десятилетия мы являемся свидетелями активно протекающего процесса изменения вклада различных стран в мировую науку. Особенности этого процесса исследуются в целом ряде работ [Radocevich, Yoruk 2014; Yang ey al. 2012; Schiermeier 2007; Рубвальтер 2018; How Putin... 2018; Markusova, Bogorov, Libkind 2018]. В этих и других отечественных и зарубежных исследованиях отмечается, что российская наука за последние 25 лет прошла ряд трудных периодов, в т.ч. связанных с сокращением финансирования и эмиграцией высококвалифицированных кадров. Известно, что имеется тесная положительная корреляция между инвестициями в научные исследования $(R \& D)$ и производством научного знания. В настоящее время на различных уровнях государственного управления приняты решения о выделении значительных дополнительных средств на развитие отечественной науки и образования, в частности решение о программе мегагрантов (постановление Правительства РФ от 9 апреля 2010 г. N 220); федеральные целевые программы Минобрнауки РФ; создание в 2013 г. Российского научного фонда (РНФ); указ Президента РФ от 07.05.2012 г. № 599 «О мерах по реализации государственной политики в области образования и науки». В связи с этим представляет несомненный интерес анализ наиболее общих характеристик состояния российской науки.

В настоящей статье рассматривается динамика формальных характеристик публикационной активности российских ученых в сопоставлении с остальными странами БРИК в трех основных научных направлениях: естествен- 
ные, точные и технические науки; общественные науки; гуманитарные науки. Исследование охватывает 25-летний период (1993-2017 гг.), т.е. практически весь постсоветский период ${ }^{1}$. В качестве источника для анализа этих характеристик были использованы базы данных (БД) информационной системы Web of Science $(W o S)$. В случае естественных, точных и технических наук использовалась БД Science Citation Index Expanded (SCI-E); в случае общественных наук - БД Social Science Citation Index (SSCI); в случае гуманитарных наук - БД Art \& Humanity Citation Index $(A \& H C I)$.

Подавляющее число публикаций российских авторов в $W o S$ составляют исследования по естественным, точным и техническим наукам. Так, на протяжении всего исследуемого периода доля российских публикаций в SCI-E от суммарного числа публикаций в указанных трех БД составляет не менее $95 \%$. И только в последние годы этот показатель начал несколько снижаться, опустившись в 2017 г. до 93,3\% (графа 2 табл. 2). Соответственно, доли двух других БД возросли: $S S C I-$ с 3,3\% в 1993 г. до 4,3\% в 2017 г. (графа 3); $A \& H C I-$ с 1,1\% в 1993 г. до 2,4\% в 2017 г. (графа 4).

На протяжении первых 15 лет (1993-2007 гг.) ежегодное число публикаций (научная продуктивность - НП) России в $S C I-E$ находится в пределах 2528 тыс. В следующие 5 лет (2008-2012 гг.) это число несколько увеличилось и составляло 30-31 тыс. документов и в этот период практически не менялось. Начиная с 2013 г. наметился довольно резкий рост этого показателя: в 2013 г. - 32726 публикаций, а в 2017 г. 40574 публикации. Ситуация с российскими публикациями в БД SSCI в первые 15 лет (1993-2007 гг.) выглядит следующим образом: в 1993 г. - 853, а в 2007 г. - 564 документа, т.е. наблюдалось падение. В следующие 7 лет (2008-2014 гг.) ежегодное число российских публикаций в SSCI заметно увеличилось: в 2014 г. это число уже составляло 1097 документов. И наконец, в последние 3 года наблюдается резкий рост этого числа, которое в 2017 г. составило 1863 документа (всего за 3 года - увеличение в 1,7 раза). Число российских публикаций в БД $A \& H C I$ в первые 15 лет, как и в случае $S C I-E$, изменялось незначительно и, как правило, не превышало 300 документов в год (исключение составляет краткий период 1996-1998 гг:: 363, 352 и 396 документов соответственно). В следующие 6 лет (2009-2014 гг.) наметилось заметное увеличение числа российских публикаций по гуманитарным наукам: в БД $A \& H C I$ в этот период ежегодное число публикаций находится в пределах 439-525 документов. При этом в последующие 3 года (2015-2017 гг.) рост числа публикаций резко усиливается, и в 2017 г. этот показатель составил уже 1064 документа. Таким образом, приведенные выше данные о динамике абсолютных показателей числа российских публикаций позволяют утверждать, что характер динамики этих показателей в рассматриваемых трех БД $W o S$ если не аналогичен, то в достаточной степени близок. Причем в последние годы во всех трех БД наблюдается резкий рост числа российских публикаций (см. графы 2-4 табл. 1).

Выше мы рассмотрели характеристики российской НП в абсолютных измерениях. Перейдем к анализу динамики НП России в измерениях относительных, а также сопоставим их значения с соответствующими значениями мирового потока в целом и с аналогичными значениями для стран БРИК - Бразилии, Индии и КНР.

\footnotetext{
1 Данные за 1992 г. не анализировались, т.к. очень многие исследователи России и других бывших республик СССР в представляемых в печать статьях «по инерции» в своих адресных данных (данных об авторе) в качестве страны указывали CCCP/USSR. Понятно, что использование таких данных не позволило бы с достаточной степенью надежности выделить публикации, принадлежащие именно ученым России.
} 
В 1993 г. доля российских публикаций от мирового потока в БД SCI-E составляла $3,265 \%^{1}$, в 2017 г. этот показатель равнялся $2,080 \%$, т.е. снизился более чем в 1,5 раза (см. графу 5 табл. 2 и рис. 1). При этом начиная с 1993 г. в течение последующих 13 лет происходит неуклонное снижение этого показателя, и в 2006 г. доля российских публикаций в $S C I-E$ падает до 2,015\%, после чего наблюдается незначительное увеличение этого показателя. Затем в 2012 г. доля российских публикаций в БД SCI-E опускается до абсолютного минимума $(1,801 \%)$. После этого начинается заметный рост: в 2017 г., как указано выше, доля российских публикаций составила 2,080\%. И это при существенном росте абсолютного числа российских публикаций в этой БД (см. табл. 1). Падение доли российских публикаций наблюдается и в общественных науках (БД $S S C I):$ с $0,671 \%$ в 1993 г. до $0,574 \%$ в 2017 г. И только в случае гуманитарных наук (БД $A \& H C I$ ) ситуация обратная: доля российских публикаций увеличивается с $0,258 \%$ в 1993 г. до 0,907\% в 2017 г., т.е. этот показатель вырос более чем в 3,5 раза, что было вызвано резким ростом числа российских публикаций (с 292 в 1993 г. до 1064 в 2017 г.). Более того, этот рост происходит в ситуации, когда в течение всего рассматриваемого периода число публикаций по гуманитарным наукам в мире росло очень медленно, а в 2017 г. практически вернулось к значению 1993 г.

Удобно представить динамику темпов роста числа российских публикаций по сравнению с аналогичной динамикой мирового потока с помощью следующего приема. Выберем, как и в предыдущем случае, период 1993-2017 гг, а в качестве показателя темпов изменения числа публикаций - отношение числа публикаций в заданном (текущем) году к числу публикаций в «нулевом» (базовом) году. В качестве базового примем 1993 г. Это отношение в каждом данном году будем вычислять для каждой из рассматриваемых БД как для российских публикаций, так и для публикаций в мировом потоке соответственно. Результаты этих вычислений приведены в графах 8-13 табл. 2, а также частично (для БД SCI-E) на рис. 2. Сопоставление этих данных показывает, что темпы роста числа отечественных публикаций по естественным, точным и техническим наукам существенно отстают от этого показателя для общемирового потока. Так, через 25 лет ежегодное число отечественных публикаций в БД $S C I-E$ увеличилось только в 1,62 раза, тогда как для мирового потока - в 2,54 раза. В случае общественных наук темпы роста числа российских публикаций также заметно отстают от соответствующих темпов мирового потока. Так, в БД SSCI число российских публикаций за 2017 г. было в 2,18 раза больше, чем в 1993 г., в то время как соответствующий показатель для мирового потока составлял 2,55. Однако в случае гуманитарных наук ситуация обратная: ежегодное число публикаций в России в БД $A \& H C I$ за 25 лет увеличилось в 3,64 раза, тогда как в случае мирового потока - только в 1,04 раза.

Здесь важно указать, что после 2011 г. темпы увеличения числа российских публикаций резко возросли и существенно превышают общемировые. Действительно, возьмем в качестве базового 2011 г. Тогда сопоставление темпов увеличения (изменения) ежегодного числа публикаций для России и мира соответственно будет выглядеть следующим образом: 1,3 и 1,2 (SCI-E); 2,0 и 1,4 $(S S C I) ; 2,42$ и $0,94(A \& H C I)$.

Проследим динамику изменения доли России в мировой науке и сопоставим с аналогичными характеристиками стран БРИК - Бразилии, Индии и КНР. С этой целью воспользуемся приемом, описанным выше. В качестве базового

\footnotetext{
1 Поскольку ежегодное число документов рассматриваемого мирового потока измеряется миллионами, а соответствующий показатель в случае России - тысячами, то такая точность (до третьего знака) представляется оправданной.
} 
Таблица 1

Число российских и мировых публикаций

\begin{tabular}{|c|c|c|c|c|c|c|}
\hline \multirow{2}{*}{$\begin{array}{c}\text { Годы } \\
\text { опубликования }\end{array}$} & \multicolumn{3}{|c|}{ Россия } & \multicolumn{3}{|c|}{ Мировой поток } \\
\hline & БД $S C I$ & БД SSCI & БД $A \& H C I$ & БД SCI & БД $S S C I$ & БД $\boldsymbol{A \& H C I}$ \\
\hline 1 & 2 & 3 & 4 & 5 & 6 & 7 \\
\hline 1993 & 25030 & 853 & 292 & 766705 & 127164 & 113027 \\
\hline 1994 & 25881 & 720 & 288 & 806303 & 131288 & 116722 \\
\hline 1995 & 27488 & 756 & 274 & 864593 & 142923 & 118107 \\
\hline 1996 & 28210 & 735 & 363 & 908890 & 148641 & 120766 \\
\hline 1997 & 28995 & 766 & 352 & 943867 & 144904 & 116491 \\
\hline 1998 & 28529 & 802 & 396 & 951553 & 142662 & 114068 \\
\hline 1999 & 28258 & 815 & 249 & 979970 & 145224 & 114070 \\
\hline 2000 & 28131 & 940 & 231 & 991467 & 153355 & 114463 \\
\hline 2001 & 26324 & 564 & 206 & 986418 & 144257 & 111601 \\
\hline 2002 & 27183 & 716 & 221 & 1034595 & 142145 & 112038 \\
\hline 2003 & 26204 & 673 & 162 & 1082925 & 146485 & 103052 \\
\hline 2004 & 26641 & 719 & 141 & 1169929 & 151291 & 95466 \\
\hline 2005 & 26670 & 541 & 251 & 1240196 & 158034 & 105829 \\
\hline 2006 & 26111 & 660 & 266 & 1295584 & 166558 & 108665 \\
\hline 2007 & 27546 & 589 & 238 & 1360697 & 181641 & 110226 \\
\hline 2008 & 29679 & 990 & 278 & 1415089 & 213661 & 120250 \\
\hline 2009 & 30152 & 805 & 439 & 1488058 & 226663 & 126846 \\
\hline 2010 & 29533 & 932 & 482 & 1521010 & 242867 & 123518 \\
\hline 2011 & 31065 & 930 & 439 & 1601243 & 256208 & 124806 \\
\hline 2012 & 30213 & 1186 & 525 & 1677573 & 271669 & 120562 \\
\hline 2013 & 32726 & 1076 & 428 & 1772788 & 277133 & 121932 \\
\hline 2014 & 33681 & 1097 & 540 & 1827016 & 280755 & 123991 \\
\hline 2015 & 37676 & 1220 & 786 & 1876525 & 293388 & 124240 \\
\hline 2016 & 39084 & 1741 & 977 & 1939967 & 313219 & 121993 \\
\hline 2017 & 40574 & 1863 & 1064 & 1950951 & 324571 & 117294 \\
\hline
\end{tabular}

года, как и прежде, примем 1993 г. Вычислим значение отношения доли данной страны в мировом потоке публикаций в текущем году к аналогичному показателю 1993 г. Сделаем это для каждой страны и для каждой области науки (в нашем случае конкретную область науки представляет конкретная база данных $W o S)$. Результаты этих вычислений показали следующее. Долю в БД SCI-E увеличили все страны БРИК: Индия - в 1,9 раза, КНР - в 14,3 раза, Бразилия - в 
Таблица 2

Динамика показателей изменения числа российских публикаций в сопоставлении с мировым потоком

\begin{tabular}{|c|c|c|c|c|c|c|c|c|c|c|c|c|}
\hline \multirow[t]{2}{*}{ 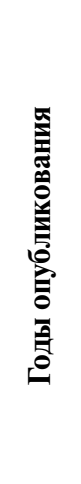 } & \multicolumn{3}{|c|}{ 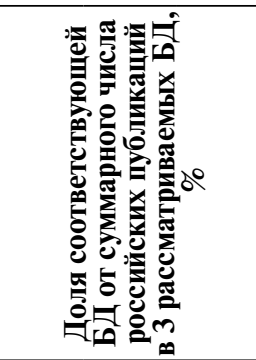 } & \multicolumn{3}{|c|}{ 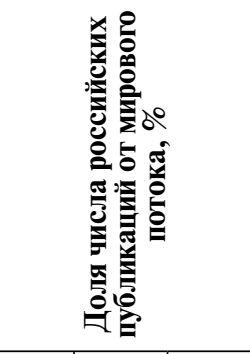 } & \multicolumn{3}{|c|}{ 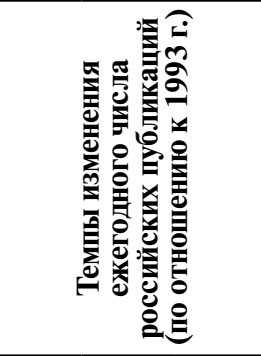 } & \multicolumn{3}{|c|}{ 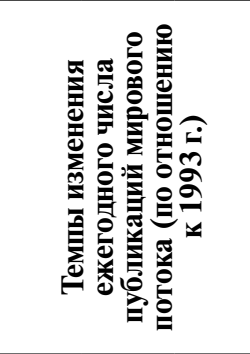 } \\
\hline & $\frac{1}{\Delta}$ & ঠ్ & 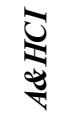 & $\frac{1}{4}$ & $\overleftarrow{\varpi}$ & 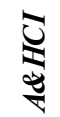 & $\frac{5}{4}$ & ঠ্ & 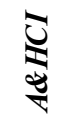 & ড্் & ঠ్ & 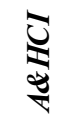 \\
\hline 1 & 2 & 3 & 4 & 5 & 6 & 7 & 8 & 9 & 10 & 11 & 12 & 13 \\
\hline 1993 & 95,6 & 3,3 & 1,1 & 3,3 & 0,7 & 0,3 & 1,00 & 1,00 & 1,00 & 1,00 & 1,00 & 1,00 \\
\hline 1994 & 96,3 & 2,7 & 1,1 & 3,2 & 0,5 & 0,2 & 1,03 & 0,84 & 0,99 & 1,05 & 1,03 & 1,03 \\
\hline 1995 & 96,4 & 2,7 & 1,0 & 3,2 & 0,5 & 0,2 & 1,10 & 0,89 & 0,94 & 1,13 & 1,12 & 1,04 \\
\hline 1996 & 96,3 & 2,5 & 1,2 & 3,1 & 0,5 & 0,3 & 1,13 & 0,86 & 1,24 & 1,19 & 1,17 & 1,07 \\
\hline 1997 & 96,3 & 2,5 & 1,2 & 3,1 & 0,5 & 0,3 & 1,16 & 0,90 & 1,21 & 1,23 & 1,14 & 1,03 \\
\hline 1998 & 96,0 & 2,7 & 1,3 & 3,0 & 0,6 & 0,3 & 1,14 & 0,94 & 1,36 & 1,24 & 1,12 & 1,01 \\
\hline 1999 & 96,4 & 2,8 & 0,8 & 2,9 & 0,6 & 0,2 & 1,13 & 0,96 & 0,85 & 1,28 & 1,14 & 1,01 \\
\hline 2000 & 96,0 & 3,2 & 0,8 & 2,8 & 0,6 & 0,2 & 1,12 & 1,10 & 0,79 & 1,29 & 1,21 & 1,01 \\
\hline 2001 & 97,2 & 2,1 & 0,8 & 2,7 & 0,4 & 0,2 & 1,05 & 0,66 & 0,71 & 1,29 & 1,13 & 0,99 \\
\hline 2002 & 96,7 & 2,5 & 0,8 & 2,6 & 0,5 & 0,2 & 1,09 & 0,84 & 0,76 & 1,35 & 1,12 & 0,99 \\
\hline 2003 & 96,9 & 2,5 & 0,6 & 2,4 & 0,5 & 0,2 & 1,05 & 0,79 & 0,55 & 1,41 & 1,15 & 0,91 \\
\hline 2004 & 96,9 & 2,6 & 0,5 & 2,3 & 0,5 & 0,1 & 1,06 & 0,84 & 0,48 & 1,53 & 1,19 & 0,84 \\
\hline 2005 & 97,1 & 2,0 & 0,9 & 2,2 & 0,3 & 0,2 & 1,07 & 0,63 & 0,86 & 1,62 & 1,24 & 0,94 \\
\hline 2006 & 96,6 & 2,4 & 1,0 & 2,0 & 0,4 & 0,2 & 1,04 & 0,77 & 0,91 & 1,69 & 1,31 & 0,96 \\
\hline 2007 & 97,1 & 2,1 & 0,8 & 2,0 & 0,3 & 0,2 & 1,10 & 0,69 & 0,82 & 1,77 & 1,43 & 0,98 \\
\hline 2008 & 95,9 & 3,2 & 0,9 & 2,1 & 0,5 & 0,2 & 1,19 & 1,16 & 0,95 & 1,85 & 1,68 & 1,06 \\
\hline 2009 & 96,0 & 2,6 & 1,4 & 2,0 & 0,4 & 0,3 & 1,20 & 0,94 & 1,50 & 1,94 & 1,78 & 1,12 \\
\hline 2010 & 95,4 & 3,0 & 1,6 & 1,9 & 0,4 & 0,4 & 1,18 & 1,09 & 1,65 & 1,98 & 1,91 & 1,09 \\
\hline 2011 & 95,8 & 2,9 & 1,4 & 1,9 & 0,4 & 0,4 & 1,24 & 1,09 & 1,50 & 2,09 & 2,01 & 1,10 \\
\hline 2012 & 94,6 & 3,7 & 1,6 & 1,8 & 0,4 & 0,4 & 1,21 & 1,39 & 1,80 & 2,19 & 2,14 & 1,07 \\
\hline 2013 & 95,6 & 3,1 & 1,3 & 1,8 & 0,4 & 0,4 & 1,31 & 1,26 & 1,47 & 2,31 & 2,18 & 1,08 \\
\hline 2014 & 95,4 & 3,1 & 1,5 & 1,8 & 0,4 & 0,4 & 1,35 & 1,29 & 1,85 & 2,38 & 2,21 & 1,10 \\
\hline 2015 & 94,9 & 3,1 & 2,0 & 2,0 & 0,4 & 0,6 & 1,51 & 1,43 & 2,69 & 2,45 & 2,31 & 1,10 \\
\hline 2016 & 93,5 & 4,2 & 2,3 & 2,0 & 0,6 & 0,8 & 1,56 & 2,04 & 3,35 & 2,53 & 2,46 & 1,08 \\
\hline 2017 & 93,3 & 4,3 & 2,4 & 2,1 & 0,6 & 0,9 & 1,62 & 2,18 & 3,64 & 2,54 & 2,55 & 1,04 \\
\hline
\end{tabular}




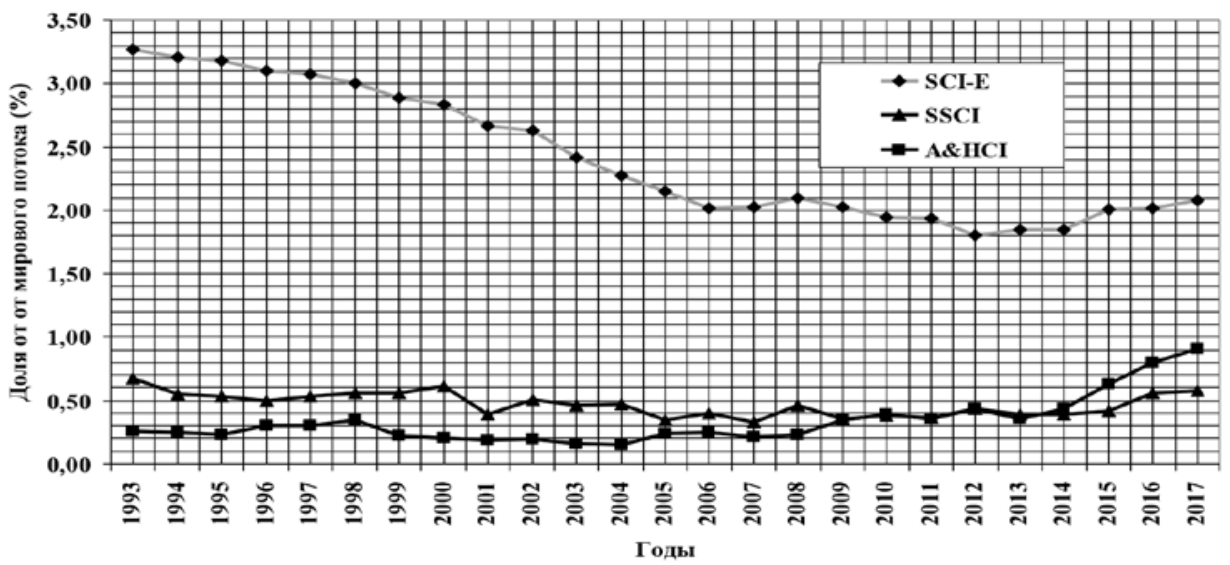

Рисунок 1. Динамика доли российских публикаций от числа публикаций мирового потока

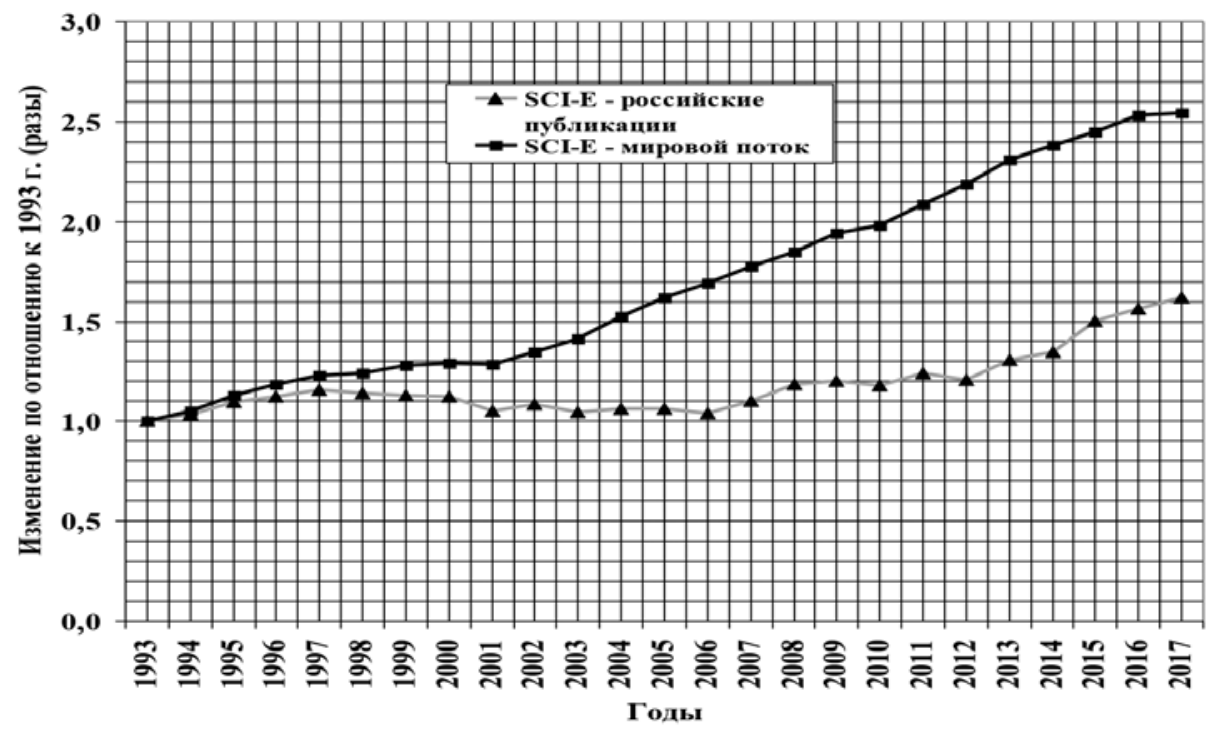

Рисунок 2. Сопоставление темпов изменения числа российских публикаций в БД $W o S S C I-E$ с аналогичными характеристиками мирового потока

4,3 раза (см. рис. 3). Исключение составляет Россия, доля которой сократилась (в 2017 г. - 0,63 доли в 1993 г). Соответственно, за это время по доле в мировом потоке Индия переместилась с 11-го места на 9-е, КНР - с 15-го на 2-е, Бразилия - с 24-го на 13-е. Аналогичная ситуация и в случае с БД SSCI: Индия - в 2,1 раза, КНР в 46,2 раза (!), Бразилия - в 9,5 раза, Россия - 0,9 (см. рис. 4). И только в случае гуманитарных наук ситуация несколько иная: Индия $-2,6$; КНР - 30,1; Бразилия - 9,3; Россия - 3,5. То есть, Россия не только увеличила свою долю в мировом потоке публикаций по гуманитарным наукам, но и по темпам роста этой доли обошла Индию.

Важной характеристикой процессов глобализации в науке являются особенности распределения публикаций по языкам. Ниже приведены краткие результаты анализа полученных нами языковых распределений отечественных 


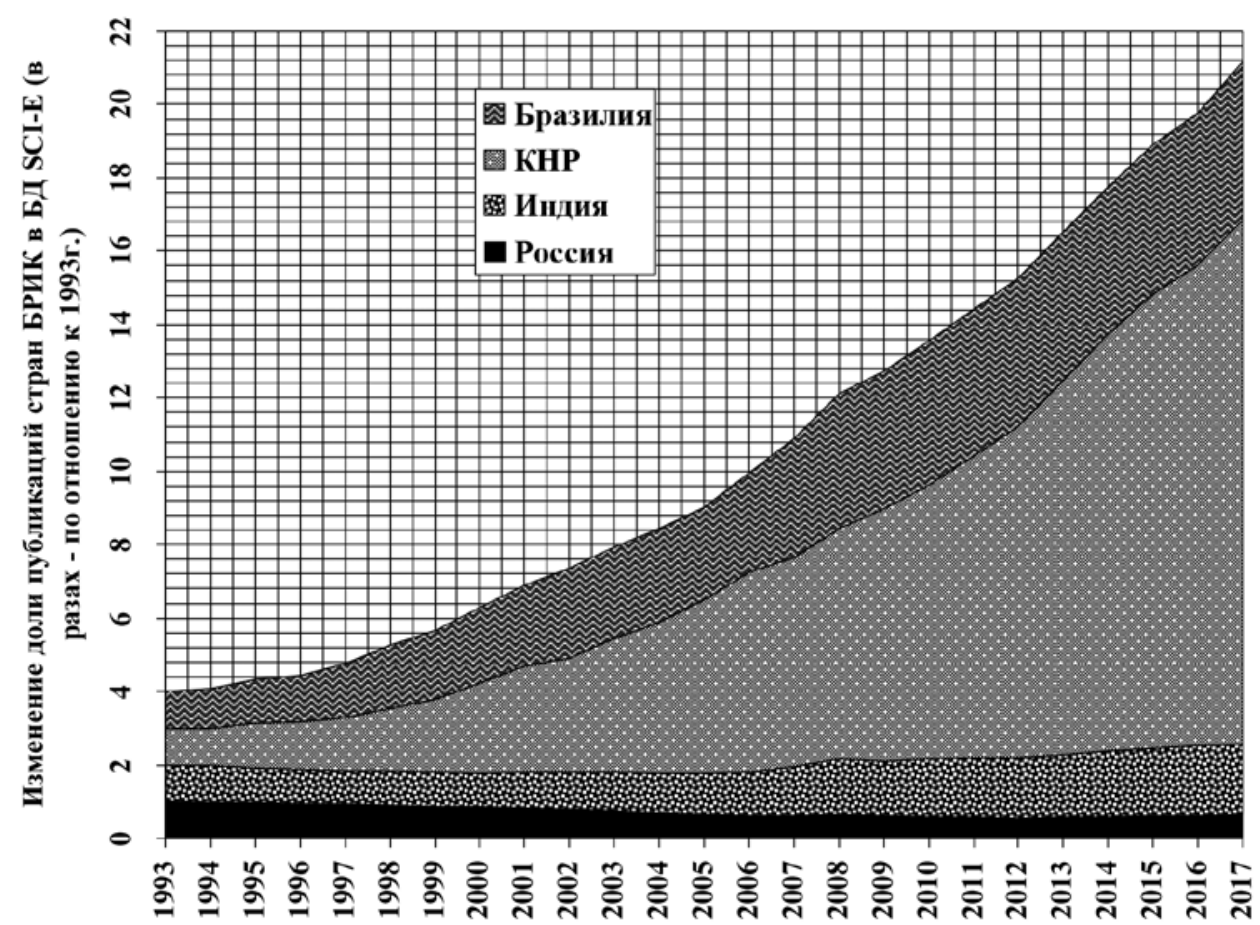

\section{Годы}

Рисунок 3. Изменение доли публикаций России и остальных стран БРИК в БД $S C I-E$

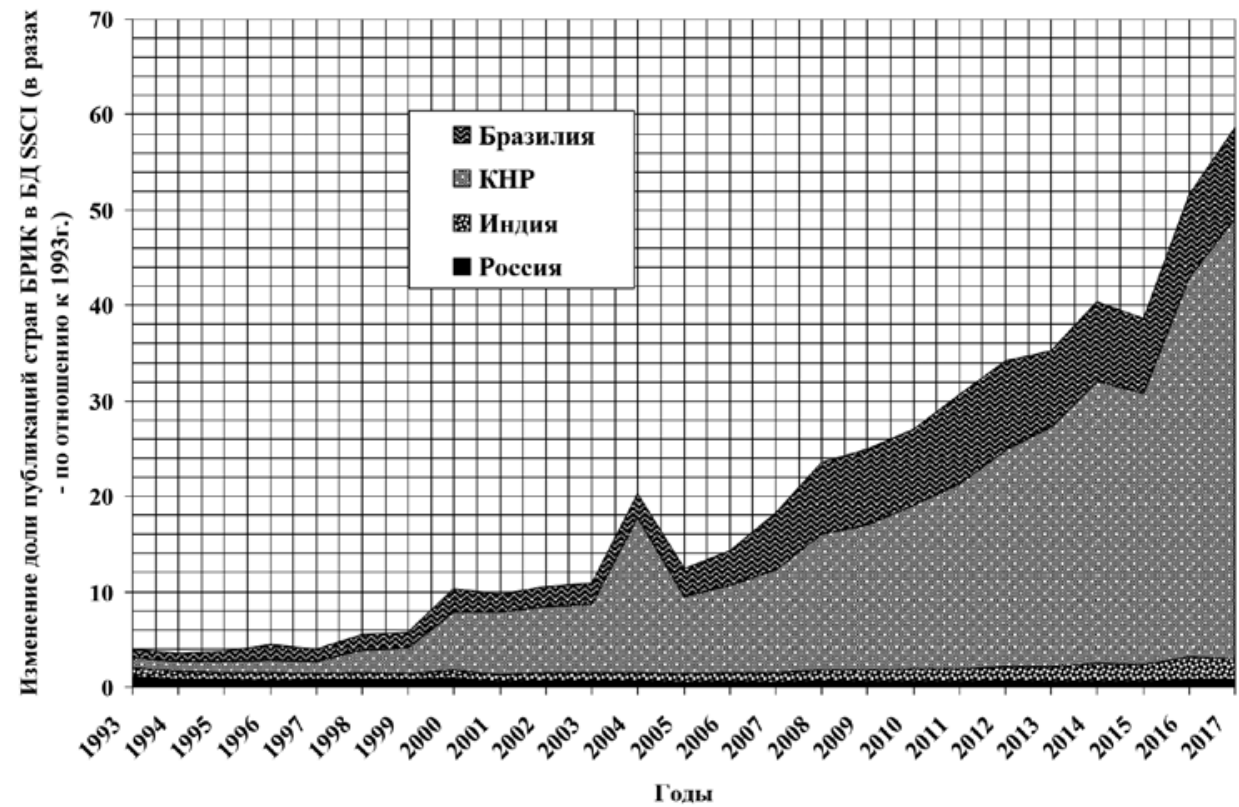

Рисунок 4. Изменение доли публикаций России и остальных стран БРИК в БД $S S C I$ 


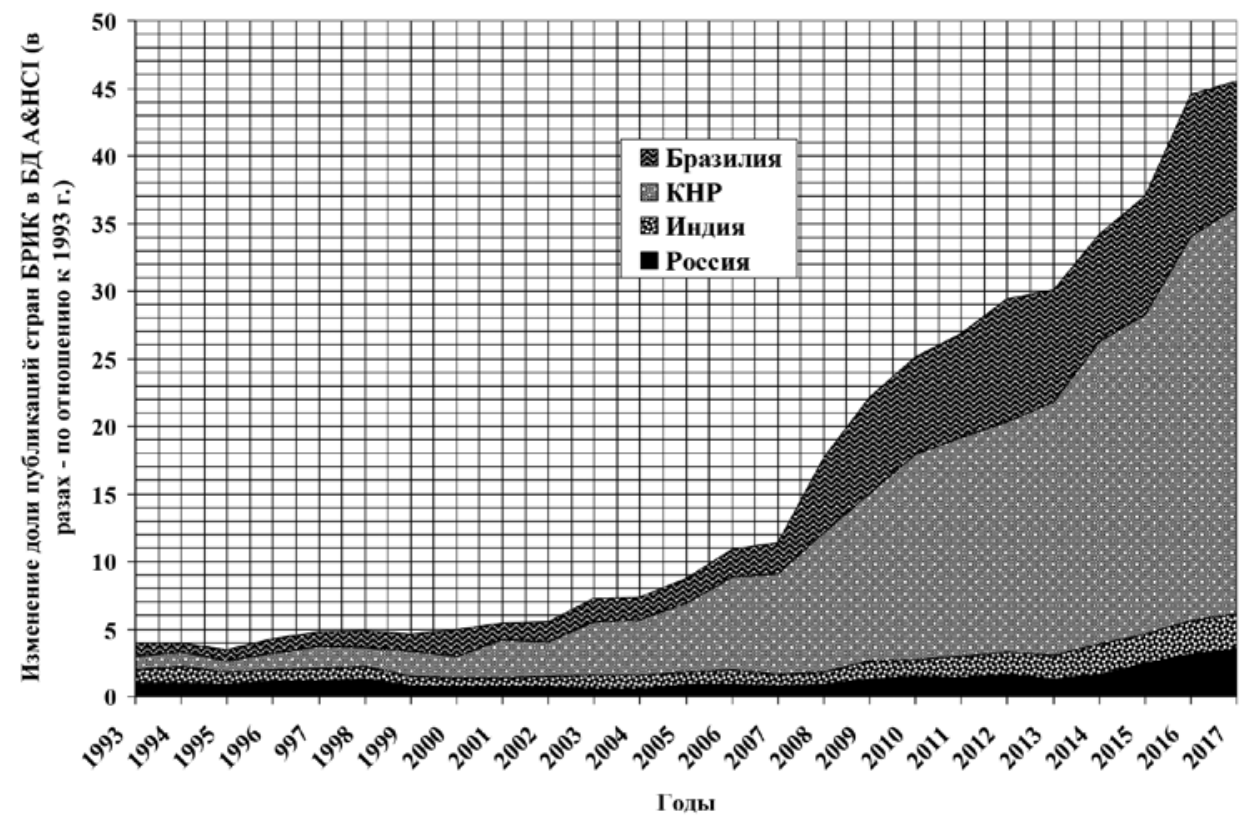

Рисунок 5. Изменение доли публикаций России и остальных стран БРИК в БД $A \& H C I$

публикаций за последние 25 лет. Как следует из табл. 3 и рис. 6, на протяжении всего исследуемого периода лидирующее положение среди публикаций по естественным, точным и техническим наукам (БД $S C I-E)$ занимают публикации на английском языке. При этом доля публикаций на этом языке на протяжении всего рассматриваемого периода постепенно увеличивается и приближается к 100\% (графа 3 табл. 3: с 60,6\% в 1993 г. до 98,3\% в 2017 г.). На 2-м месте - публикации на русском языке. Причем доля публикаций на русском языке резко падает: с 39,3\% в 1993 г. до 1,6\% в 2017 г., т.е. за 25 лет этот показатель уменьшился почти в 25 раз (графа 2 табл. 3). Интересно отметить, что это падение происходит практически синхронно с ростом доли публикаций на английском языке. Публикации на остальных 10-15 языках составляют примерно 0,1\%. В случае общественных наук (БД SSCI) первые годы (1993-1996) отечественные публикации на русском языке делят первые и вторые места (около 50\%) с англоязычными. Начиная с 1997 г. доля публикаций на русском языке вначале медленно, а затем все быстрее снижается и к 2017 г. достигает минимума (21\%). Тем не менее этот показатель для общественных наук намного выше, чем в случае естественных, точных и технических наук. Так, в 2017 г. доля отечественных публикаций на русском языке в БД SSCI в 13 раз выше, чем соответствующее значение для БД $S C I-E(21,0 \%$ против 1,6\%). Начиная с 1997 г. и до конца исследуемого периода 1-е место среди отечественных публикаций в БД SSCI занимают отечественные публикации на английском языке. В целом, на протяжении всех 25 лет их доля возрастает: с 46,5\% в 1993 г. до 77,7\% в 2017 г. Доля публикаций на остальных языках колеблется в пределах 1,0-4,7\% и характеризуется тенденцией к снижению. Что касается российских публикаций по гуманитарным наукам, то здесь на протяжении всего 25-летнего периода 1-е место занимают публикации на русском языке. При этом их доля, правда, очень медленно, снижается: с 67,5\% в 1993 до 61,4\% в 2017 г. Доля остальных языков 
в большинстве случаев колеблется в пределах $3-5 \%$ и также характеризуется тенденцией к снижению.

Таблица 3

Распределение по языкам российских публикаций в базах данных WoS, \%

\begin{tabular}{|c|c|c|c|c|c|c|c|c|c|}
\hline \multirow[b]{2}{*}{ Год } & \multicolumn{3}{|c|}{ БД $S C I-E$} & \multicolumn{3}{|c|}{ БД $S S C I$} & \multicolumn{3}{|c|}{ БД $A \& H C I$} \\
\hline & 氞 & 罯 & 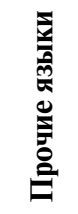 & لِ & 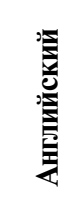 & 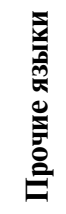 & 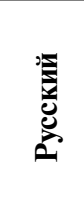 & 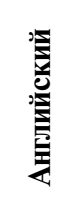 & 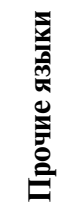 \\
\hline 1 & 2 & 3 & 4 & 5 & 6 & 7 & 8 & 9 & 10 \\
\hline 1993 & 39,3 & 60,6 & 0,1 & 50,6 & 46,5 & 2,8 & 67,5 & 28,1 & 4,5 \\
\hline 1994 & 36,9 & 63,0 & 0,1 & 46,5 & 50,0 & 3,5 & 63,5 & 31,9 & 4,5 \\
\hline 1995 & 32,3 & 67,6 & 0,1 & 47,4 & 48,8 & 3,8 & 65,3 & 31,4 & 3,3 \\
\hline 1996 & 31,6 & 68,3 & 0,1 & 45,2 & 52,5 & 2,3 & 59,2 & 34,2 & 6,6 \\
\hline 1997 & 24,3 & 75,6 & 0,1 & 50,8 & 47,1 & 2,1 & 66,2 & 30,7 & 3,1 \\
\hline 1998 & 21,8 & 78,1 & 0,1 & 45,8 & 52,2 & 2,0 & 67,9 & 26,3 & 5,8 \\
\hline 1999 & 18,1 & 81,8 & $<0,1$ & 47,5 & 50,6 & 2,0 & 58,6 & 33,3 & 8,0 \\
\hline 2000 & 11,7 & 88,2 & 0,1 & 39,1 & 58,5 & 2,3 & 44,6 & 45,9 & 9,5 \\
\hline 2001 & 5,2 & 94,7 & 0,1 & 47,2 & 50,0 & 2,8 & 34,5 & 48,1 & 17,5 \\
\hline 2002 & 7,8 & 92,1 & 0,1 & 44,3 & 53,8 & 2,0 & 47,1 & 46,2 & 6,8 \\
\hline 2003 & 6,4 & 93,5 & 0,1 & 54,5 & 43,1 & 2,4 & 42,0 & 51,2 & 6,8 \\
\hline 2004 & 5,7 & 94,2 & 0,0 & 43,7 & 55,5 & 0,8 & 52,5 & 41,8 & 5,7 \\
\hline 2005 & 5,3 & 94,7 & 0,0 & 36,0 & 60,4 & 3,5 & 53,0 & 41,0 & 6,0 \\
\hline 2006 & 4,7 & 95,2 & 0,1 & 34,5 & 63,8 & 1,7 & 59,8 & 39,1 & 1,1 \\
\hline 2007 & 4,7 & 95,2 & 0,1 & 36,3 & 61,5 & 2,2 & 66,8 & 27,7 & 5,5 \\
\hline 2008 & 4,0 & 95,9 & 0,1 & 14,9 & 82,8 & 2,2 & 63,7 & 32,0 & 4,3 \\
\hline 2009 & 3,8 & 96,1 & 0,1 & 38,3 & 58,0 & 3,7 & 63,1 & 32,1 & 4,8 \\
\hline 2010 & 3,9 & 96,1 & $<0,1$ & 34,9 & 63,4 & 1,7 & 68,5 & 29,9 & 1,7 \\
\hline 2011 & 4,0 & 95,9 & $<0,1$ & 35,3 & 63,0 & 1,7 & 65,4 & 31,9 & 2,7 \\
\hline 2012 & 4,1 & 95,8 & $<0,1$ & 31,4 & 66,3 & 2,4 & 62,5 & 33,3 & 4,2 \\
\hline 2013 & 3,2 & 96,7 & $<0,1$ & 27,3 & 71,3 & 1,4 & 55,6 & 38,1 & 6,3 \\
\hline 2014 & 2,1 & 97,8 & $<0,1$ & 22,8 & 75,6 & 1,6 & 54,4 & 40,4 & 5,2 \\
\hline 2015 & 1,9 & 98,0 & $<0,1$ & 24,7 & 74,5 & 0,8 & 60,6 & 34,4 & 5,1 \\
\hline 2016 & 1,8 & 98,1 & $<0,1$ & 22,9 & 76,1 & 1,0 & 60,6 & 35,6 & 3,2 \\
\hline 2017 & 1,6 & 98,3 & $<0,1$ & 21,0 & 77,7 & 1,3 & 61,4 & 34,7 & 3,2 \\
\hline
\end{tabular}




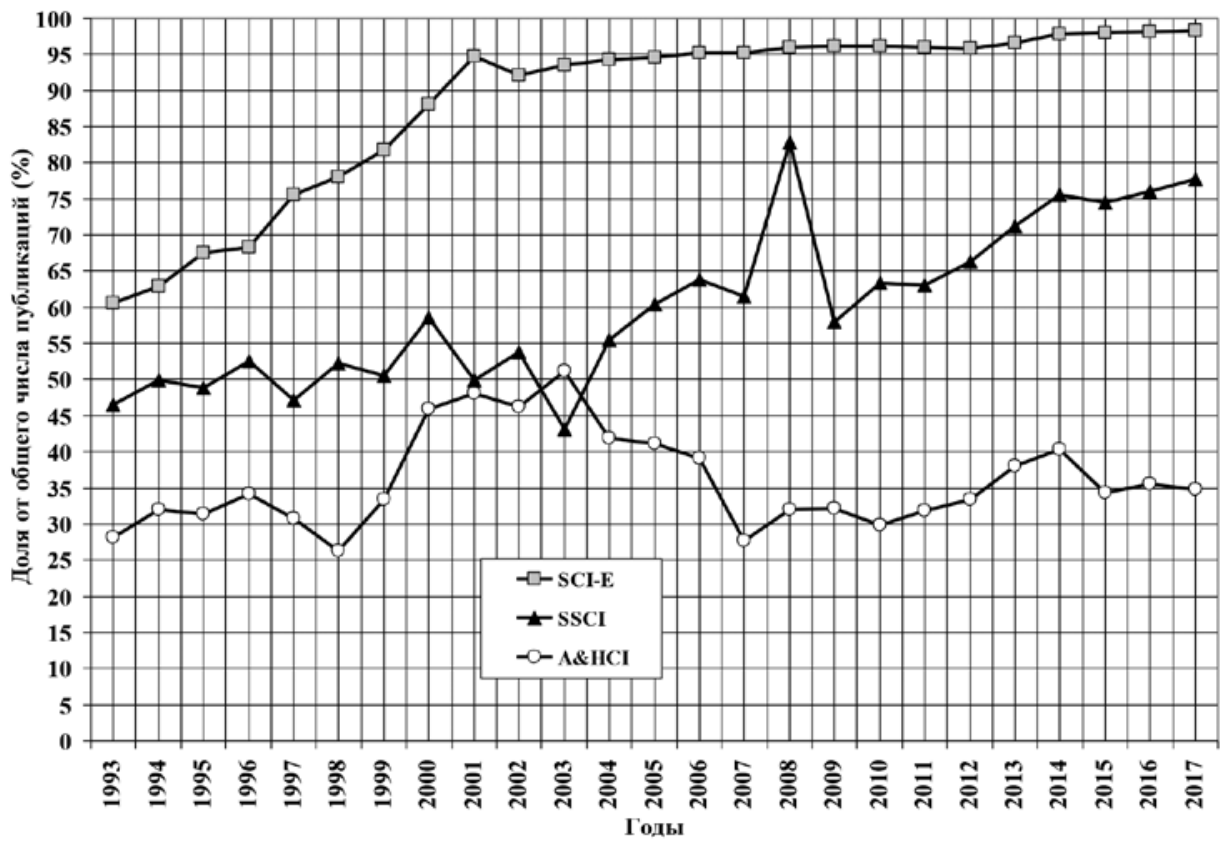

Рисунок 6. Динамика изменения доли публикаций на английском языке (от общего числа российских публикаций)

Еще одной характеристикой процесса глобализации российской науки могут служить следующие показатели, характеризующие участие в российских публикациях ученых из различных стран (соответствующие численные показатели приведены в табл. 4):

- среднее число уникальных (неповторяющихся) стран, включая Россию, ученые из которых выступали в качестве соавторов некоторой средней российской публикации; данные рассчитаны по всему массиву российских публикаций в данном году (этому показателю в табл. 4 соответствуют графы 1, 7 и 13);

- среднее число неуникальных (повторяющихся) стран, включая Россию, ученые из которых выступали в качестве соавторов некоторой средней российской публикации; данные рассчитаны по всему массиву российских публикаций (этому показателю в табл. 4 соответствуют графы 2, 8 и 14);

- среднее число уникальных стран, включая Россию, ученые из которых выступали в качестве соавторов некоторой средней российской публикации при условии, что в каждой из таких публикаций участвовал (был соавтором) хотя бы один ученый из зарубежной страны (этому показателю в табл. 4 соответствуют графы 3,9 и 15);

- среднее число неуникальных стран, включая Россию, ученые из которых выступали в качестве соавторов некоторой средней российской публикации при условии, что в каждой из таких публикаций участвовал (был соавтором) хотя бы один ученый из зарубежной страны (этому показателю в табл. 4 соответствуют графы 4, 10 и 16);

- среднее число уникальных зарубежных стран, ученые из которых выступали в качестве соавторов некоторой средней российской публикации (этому показателю в табл. 4 соответствуют графы 5, 11 и 17); 
Таблица 4

Динамика показателей, характеризующих соавторство на уровне стран*

\begin{tabular}{|c|c|c|c|c|c|c|c|c|c|c|c|c|c|c|c|c|c|c|}
\hline \multirow{2}{*}{ Годы } & \multicolumn{6}{|c|}{ SCI-E } & \multicolumn{6}{|c|}{ SSCI } & \multicolumn{6}{|c|}{ A\&HCI } \\
\hline & 1 & 2 & 3 & 4 & 5 & 6 & 7 & 8 & 9 & 10 & 11 & 12 & 13 & 14 & 15 & 16 & 17 & 18 \\
\hline 2006 & 1,7 & 2,7 & 2,8 & 5,0 & 1,8 & 3,7 & 1,5 & 1,9 & 3,2 & 4,2 & 2,3 & 3,0 & 1,1 & 1,2 & 2,6 & 4,0 & 1,6 & 2,7 \\
\hline 2007 & 1,7 & 2,8 & 2,9 & 5,5 & 1,9 & 4,2 & 1,5 & 2,0 & 2,8 & 4,2 & 1,8 & 2,9 & 1,1 & 1,2 & 2,4 & 3,7 & 1,4 & 2,3 \\
\hline 2008 & 1,6 & 2,8 & 3,0 & 5,8 & 2,0 & 4,4 & 1,4 & 1,8 & 2,8 & 3,9 & 1,9 & 2,6 & 1,1 & 1,2 & 2,2 & 3,4 & 1,2 & 2,0 \\
\hline 2009 & 1,6 & 2,8 & 3,0 & 6,0 & 2,0 & 4,6 & 1,5 & 2,0 & 3,1 & 4,5 & 2,1 & 3,3 & 1,2 & 1,3 & 3,8 & 5,3 & 2,9 & 4,2 \\
\hline 2010 & 1,7 & 2,9 & 3,1 & 6,1 & 2,1 & 4,6 & 1,6 & 2,1 & 3,2 & 4,8 & 2,3 & 3,5 & 1,1 & 1,3 & 2,4 & 3,7 & 1,4 & 2,4 \\
\hline 2011 & 1,7 & 2,9 & 3,1 & 6,1 & 2,1 & 4,7 & 1,4 & 2,0 & 2,7 & 3,9 & 1,7 & 2,4 & 1,1 & 1,3 & 2,5 & 3,2 & 1,5 & 2,1 \\
\hline 2012 & 1,7 & 3,1 & 3,3 & 6,9 & 2,3 & 5,4 & 1,7 & 2,4 & 3,4 & 5,6 & 2,4 & 4,3 & 1,1 & 1,3 & 2,5 & 3,7 & 1,6 & 2,5 \\
\hline 2013 & 1,8 & 3,3 & 3,3 & 6,8 & 2,3 & 5,2 & 1,6 & 2,3 & 2,9 & 4,4 & 2,0 & 3,0 & 1,2 & 1,4 & 2,4 & 3,8 & 1,5 & 2,2 \\
\hline 2014 & 1,9 & 3,6 & 3,5 & 7,2 & 2,5 & 5,5 & 1,8 & 2,6 & 3,1 & 4,7 & 2,2 & 3,5 & 1,2 & 1,6 & 3,1 & 4,7 & 2,1 & 3,3 \\
\hline 2015 & 1,9 & 3,6 & 3,5 & 6,9 & 2,5 & 5,1 & 2,0 & 2,8 & 3,3 & 4,8 & 2,4 & 3,6 & 1,2 & 1,6 & 2,7 & 4,1 & 1,8 & 2,8 \\
\hline
\end{tabular}

* Пояснения к графам настоящей таблицы см. выше.

- среднее число неуникальных зарубежных стран, ученые из которых выступали в качестве соавторов некоторой средней российской публикации (этому показателю в табл. 4 соответствуют графы 6, 12 и 18).

Детальный анализ и истолкование приведенных в табл. 4 значений показателей соавторства российских ученых на уровне стран потребует привлечения дополнительных данных, которые мы предполагаем получить в будущем. Здесь только отметим следующее. Во-первых, все приведенные в табл. 4 значения показателей соавторства характеризуются положительной динамикой. Во-вторых, наиболее активно сотрудничают с коллегами (отечественными и зарубежными) те российские ученые, которые заняты исследованиями в области естественных, точных и технических наук. Затем следуют российские ученые, занятые исследованиями в области общественных наук. Гуманитарные исследования характеризуются существенно более низкой степенью и отечественного, и зарубежного соавторства. Особенно четко это видно на рис 7.

Полученные в настоящей работе данные позволяют утверждать следующее. Исследования по естественным, точным и техническим наукам (hard science) по-прежнему доминируют в российской науке - наследнице науки советской. Правда, с течением времени доля публикаций по этой проблематике несколько сократилась, однако все еще составляет более $93 \%$ общего числа российских публикаций, представленных в авторитетной международной системе Web of Science. Соответственно, доля публикаций по общественным наукам, а также по гуманитарным наукам за 1993-2017 гг. несколько возросла: с 3,3\% до 4,3\% и с $1,1 \%$ до $2,4 \%$ соответственно.

В то время как Индия, КНР и Бразилия за рассматриваемый период существенно увеличили свою долю в мировом потоке по всем 3 рассматриваемым направлениям фундаментальных исследований, доля России заметно снизилась как в естественных, точных и технических науках, так и в общественных. И только в гуманитарных науках эта доля возросла, причем очень существенно - 


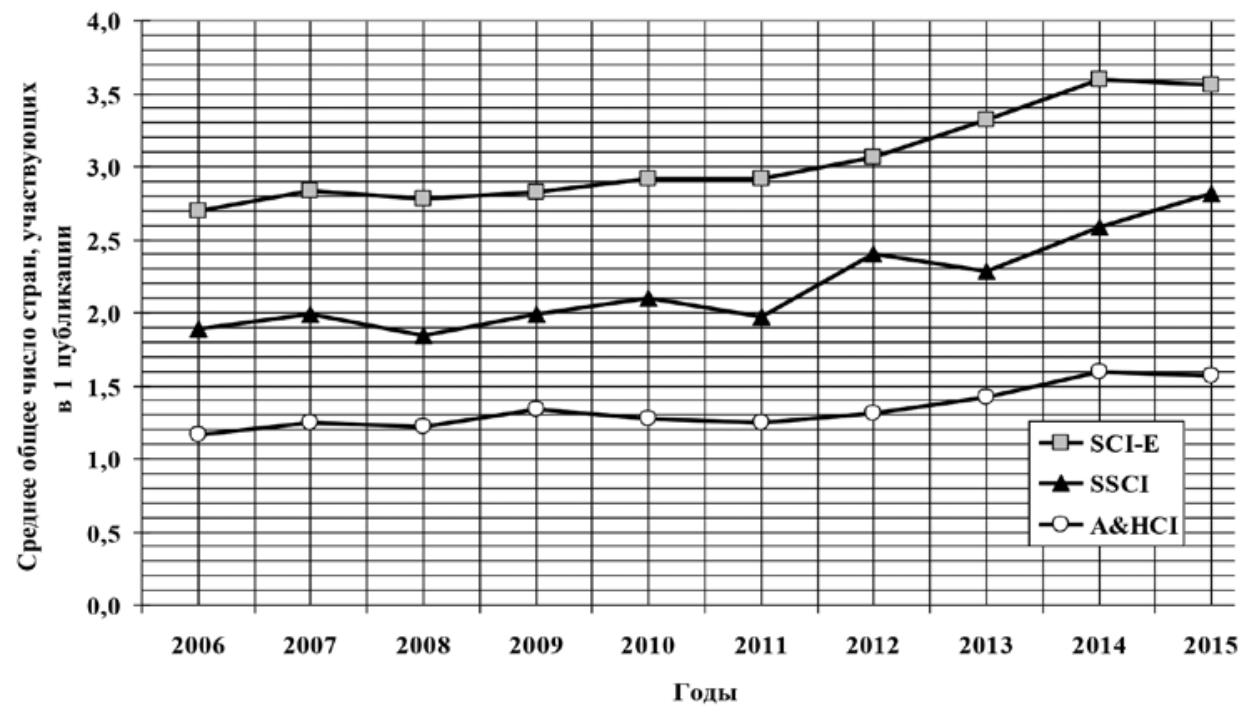

Рисунок 7. Сопоставление значений среднего числа неуникальных (повторяющихся) стран (включая Россию) для различных научных областей в расчете на 1 российскую публикацию

более чем в 3,5 раза. Здесь важно отметить, что в последние годы ситуация стала меняться, причем в лучшую сторону: во всех 3 областях темпы относительного прироста числа российских публикаций после 2011 г. оказывается выше, чем аналогичный показатель для мира в целом.

В течение рассматриваемого периода российская наука все более включалась в процесс глобализации. Действительно, резко увеличилась доля российских публикаций на английском языке. В естественных, точных и технических науках этот показатель возрос с 60,6\% до 98,3\%. В общественных науках - с 46,5\% до 77,7\%. Усилия российских ученых добиться более широкого использования результатов их исследований с помощью опубликования этих результатов на английском языке были приложены и в гуманитарных науках: доля отечественных публикаций на английском языке увеличилась с $28,1 \%$ до $34,7 \%$. Можно предположить, что существенные различия в этих цифрах связаны с природой и особенностями каждой из этих научных областей. О все более активном вовлечении российской науки в процесс глобализации свидетельствует и то, что во всех трех рассматриваемых областях фундаментальной науки все активнее происходит международное сотрудничество, что проявляется в росте числа стран, ученые из которых участвуют в российских публикациях.

Настоящее исследование было частично поддержано Российским фондом фундаментальных исследований (проекты РФФИ: 17-0200078, 17-02-00157).

\section{Список литературы}

Рубвальтер Д.А. 2018. О вкладе науки в реализацию экономической политики. - Власть. № 1. С. 22-29.

How Putin Can Restore Russian Research. The Sleeping Bear of Russian Science 
Could Finally Wake - and China Can Show It How: Editorial. 2018. - Nature. Vol. 555. No. 7696. P. 285-286.

Markusova V., Bogorov V., Libkind A. 2018. Usage Metrics vs Classical Metrics: Analysis of Russia's Research Output. - Scientometrics. Vol. 114. No. 3. P. 593-603.

Radocevich R., Yoruk L. 2014. Are there Global Shifts in the World Science Base? Analysing the Catching up and Falling behind of World Regions. - Scientometrics. Vol. 101. No. 3. P. 1897-1924.

Schiermeier Q. 2007. The Battle for Russia’s Brains. - Nature. Vol. 449. No. 7162. P. 524-527.

Yang L.Y., Yue T., Ding J.L., Han T. 2012. A Comparison of Disciplinary Structure in Science between the G7 and the BRIC Countries by Bibliometric Methods. Scientometrics. Vol. 93. No. 2. P. 497-516.

RUBVALTER Dmitriy Aleksandrovich, Dr.Sci. (Econ.), Professor, Advisor to the Director of the Moscow Centre for Technological Modernization of Education «Democenter» (3, $1^{\text {st }}$ Zborovsky Lane, Moscow, Russia, 107076; dmitry. rubvalter@yandex.ru)

MARKUSOVA Valentina Aleksandrovna, Dr.Sci. (Ped.), Head of the Department of All-Russian Institute for Scientific and Technical Information, RAS (20 Usievicha St, Moscow, Russia, 140010; valentina.markusova@gmail.com) LIBKIND II'ya Aleksandrovich, Analyst, Service Bureau VIP (65 Perovskaya St, Moscow, Russia, 111394; ilya_libkind@ hotmail.com)

KAMEN' Natal'ya Markovna, Senior Researcher of All-Russian Institute for Scientific and Technical Information, RAS (20 Usievicha St, Moscow, Russia, 140010; natakhak@mail.ru)

LIBKIND Aleksandr Naumovich, Cand.Sci. (Techn.), Leading Researcher of All-Russian Institute for Scientific and Technical Information, RAS (20 Usievicha St, Moscow, Russia, 140010; anliverty@mail.ru)

\section{DYNAMICS OF CHARACTERISTICS OF PUBLICATION ACTIVITY IN THE RUSSIAN FUNDAMENTAL SCIENCE IN COMPARISON WITH THE BRIC COUNTRIES}

\footnotetext{
Abstract. The authors analyze a number of formal parameters characterizing the publication activity of Russian scientists in comparison with the BRIC countries and the global flow of publications in general. In particular, it is the dynamics of the annual number of publications, the rate of change in this number, the dynamics of changes in the share of publications in the world stream, the distribution of Russian publications by language of their publication, co-authorship at the country level. The analysis covers the period 1993-2017 and is based on the processing of Web of Science data.

Keywords: publication activity, Russian science, BRIC countries, scientometrics, Web of Science
} 